\title{
Problems concerning reconstruction of old post- industrial building of a closed coal mine and its adaptation to a new utility function
}

\author{
Jacek Hulimka*, Jan Kubica, and Marta Kałuża \\ Silesian University of Technology, Gliwice, Poland
}

\begin{abstract}
The waiting room and bath building is one of the two preserved industrial facilities of the former Gliwice Mine. It was built in the first years of the $20^{\text {th }}$ century and fulfilled its function till mine liquidation in 2000. It was overhauled and modernized in 2005-2008 and currently fulfills a new function. The paper presents a summarized history of the Gliwice Mine, a detailed description of the building structure, its technical condition before the overhaul and problems encountered during the adaptation works. It also briefly indicates the causes of the observed damage as well as describes the scope of the basic modernization works related to the new function of the building as an education and office facility. Moreover, it presents the manner of conducting the overhaul and modernization works leading to restoration of the full utility values in the new function.
\end{abstract}

\section{A short history}

The Gliwice Coal Mine dates back to the beginning of the $20^{\text {th }}$ century. On June $26^{\text {th }}, 1901$, sixteen mining fields with a total surface area of $24.09 \mathrm{~km}^{2}$ belonging to William Suermondt from Wrocław (Breslau) and other German owners were joined to form one enterprise [1].

In 1909, sinking of two extraction shafts was commenced with the use of tubing due to the presence of quicksand. In 1911, the first extraction level was established at a depth of $185 \mathrm{~m}$. Coal extraction from approx. $1 \mathrm{~m}$ thick beds began in 1912. The extracted mineral was coking coal of very high quality, high calorific value and low sulfur content [2].

From the beginning of operation till 1945, the mine worked under the name of Gleiwitzgrube and had several owners, the last of which was Borsig Kokswerke AG. The extraction capacity of the mine grew steadily during that period, from 13,786 tons in 1912, through 555,000 tons in 1930 , to as many as 878,608 tons in 1943 (with 2,362 employees) $[3,4]$.

In 1945, the Soviet occupation authorities decided to flood the lowest level (520), while some devices (including a modern washing system) were disassembled and carried away. The production was resumed on April $9^{\text {th }}, 1945$ and the extraction capacity achieved in May reached 1,913 tons (that is, only $2.6 \%$ of the average productivity in 1943).

\footnotetext{
${ }^{*}$ Corresponding author: jacek.hulimka@polsl.pl
} 
Beside the construction of the underground infrastructure, accompanying facilities had been built since the beginning of mine existence. The three biggest ones were: the waiting room and bath building, the engine house and the boiler house (the latter was disassembled after an explosion that took place in the 1950s). Those monumental buildings, as well as the still existing employee houses located at today's Pszczyńska Street in Gliwice (mine owners paid attention to their employees' accommodation problems, also in Upper Silesia - see [5]), were created by well-known and valued architects from Berlin-Charlottenburg - brothers Emil and Georg Zillmann. They also created, among other things, the workers' housing estates in Nikiszowiec and Giszowiec.

After World War II, the mine operated under the name of KWK Gliwice and existed until 2000, when it was closed. In 2005, after five years of deterioration of the unused facilities, overhaul and modernization works were commenced. They covered the former waiting room and bath building and the former engine house due to the planned complete change of their utility functions to education and office facilities. Both facilities were opened in 2008. The waiting room and bath building, to which this paper is devoted, currently houses the Gliwice School of Entrepreneurship (GWSP), a college focusing on economic sciences, humanities and arts, and the House for Polish-German Cooperation (DWPN), while the renovated former engine house is now the seat of, among others, the Museum of Artistic Foundry (MOA). One can also find there office spaces for rent as part of a business incubator.

\section{Description of the former waiting room and chain bath building}

The subject of this paper is the former waiting room and chain bath building - one of the two preserved facilities of the former mine (Fig. 1). The description below concerns the original structure existing before the modernization and adaptation to the new function.

The building is rectangular. Its approximate outline dimensions are $36.1 \times 82.4 \mathrm{~m}$ and its height to the ridge is $24.3 \mathrm{~m}$. There is a tower with a total height of $44.0 \mathrm{~m}$ in the middle of the building outline. There are also cellars under the entire facility. The main body of the building is divided into a lower two-floor encircling part and a higher inside part. The latter also has two floors, the second of which is high and forms one room in each of the two wings. Those two big rooms originally fulfilled the functions of a waiting room and a bath.

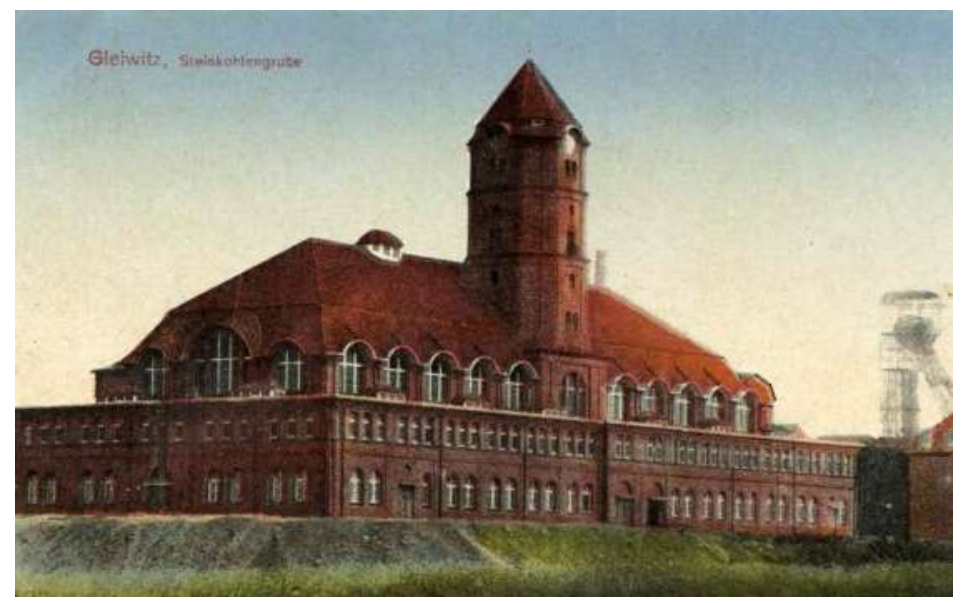

Fig. 1. A north-western general view of the waiting room building (an archive photo, http://fotopolska.eu/354686,foto.html)

The load-bearing structure of both main wings is a wall structure with a longitudinal layout, made from ceramic bricks (Fig. 2). The cellars and the first floor feature not only 
load-bearing walls, but also brick pillars made from full bricks. The load-bearing structure is supported on direct foundations (footings and bases) made from full bricks and seated approx. $4 \mathrm{~m}$ below ground level.

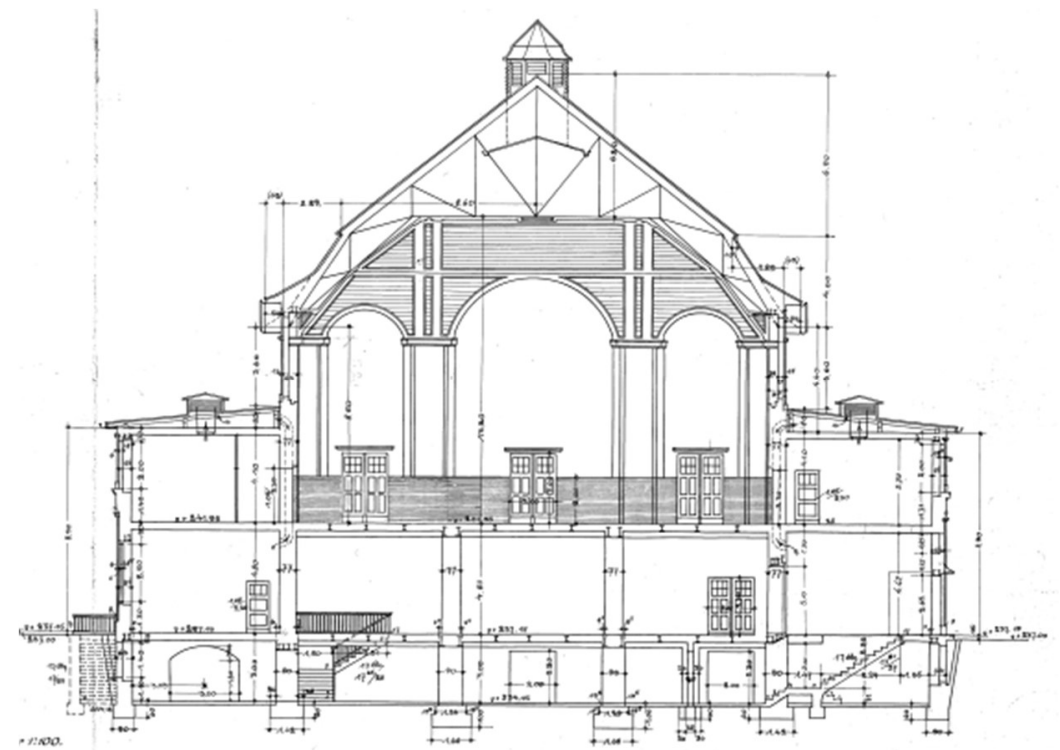

Fig. 2. A cross-section of the northern wing (a stock-taking drawing from 1964, author's archive)

The cellar ceiling (Fig. 3) is a brick segmental barrel vault supported on the walls and steel beams (ribs). The steel ribs rest either on the load-bearing walls or binding joists made from steel beams with brick filling (supported on the walls or pillars).

The first floor ceiling (Fig. 4) is a ceramic and steel infill floor Klein type. The beams rest on the load-bearing walls or steel binding joists. The ceiling slab is reinforced with hoop iron and features special structural clay tiles (commonly used in the region at the turn of the $19^{\text {th }}$ and $20^{\text {th }}$ centuries) which reduce the ceiling weight compared to a typical ceiling with the slab made from full bricks.

Most of the stairs and landings are monolithic constructions made of reinforced concrete. Exceptions are the steel and wooden formal stairs in the main hall and the steel stairs on the upper floors of the tower.

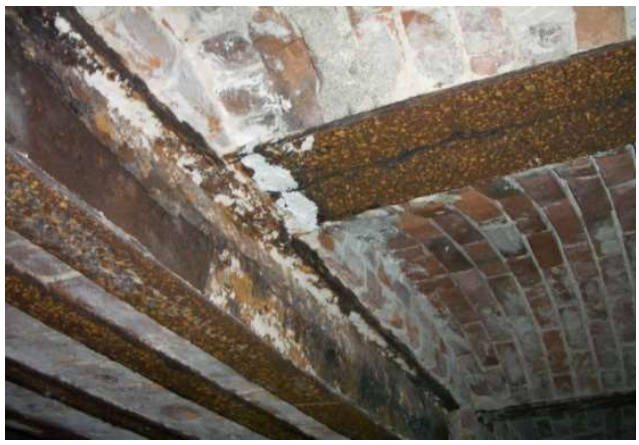

Fig. 3. The cellar ceiling: steel ribs and a binding joist fragment (note the corrosion of steel)

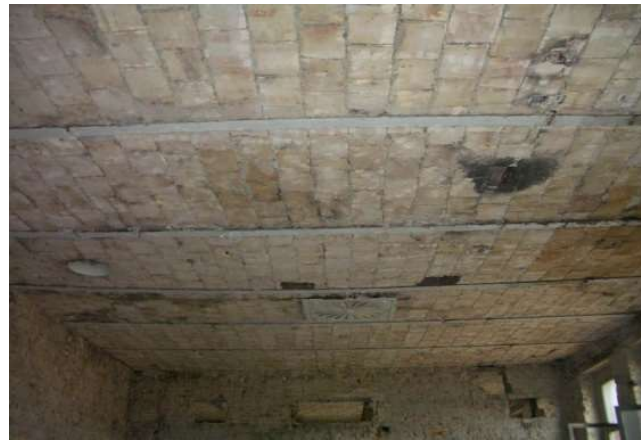

Fig. 4. The first floor ceiling: steel ribs and structural clay tiles (note the rib sagging)

The encircling (lower) part of the building has a ventilated flat roof consisting of a loadbearing layer in the form of an infill floor (like the one above the first floor) and a wooden 
structure of a monopitch roof supported on it. The roof slope in this part is made of roofing paper laid on full boarding. The higher parts of both wings have a gable roof with a steel and wooden load-bearing structure (Fig. 2). The main girders are riveted triangular (A-shaped) trusses spaced every $5.6 \mathrm{~m}$. The girders support trussed purlins (which also act as longitudinal braces) or riveted purlins made from rolled sections. The outermost girders are lowered to ensure transverse roof slopes. The secondary load-bearing elements are wooden. The roof slope is covered with ceramic roofing tiles on battens. The main roof slopes are broken and have windows in their lower parts. The lower flanges of the girders support longitudinal wooden elements (Fig. 5) which hold a suspended ceiling structure - a wooden one in the southern wing (Fig. 6) and one made of reinforced concrete (a $45 \mathrm{~mm}$ thick slab) in the northern wing (Fig. 7).

There is a tower in the middle of the building outline on the western side. The dimensions of the tower are approx. $10.0 \times 10.0 \mathrm{~m}$ in the top view (which changes slightly on the individual floors) and its height reaches $44.0 \mathrm{~m}$. The transverse walls of the tower in the outline of the main building body reach down to the foundations and mark off the main hall on the first floor. The longitudinal walls rest on riveted steel binding joists supported on the transverse walls. The tower outline above the binding joist level is octagonal; its oblique walls are supported on secondary binding joists. The tower has a mixed structure, that is, a wall structure made from full bricks with local reinforcements in the form of riveted steel sections. Encircling ties made from steel bars joined by welding are embedded in several floors of the tower.

There are three intermediate ceilings in the tower. They have a steel and ceramic infill structure (with binding joists and ribs made of steel and flush in the lower plane - Fig. 8). The lowest ceiling is accessed via a staircase located on the eastern side of the tower, within the attic. The higher levels are accessed via encircling steel stairs fixed to the wall (Fig. 8).

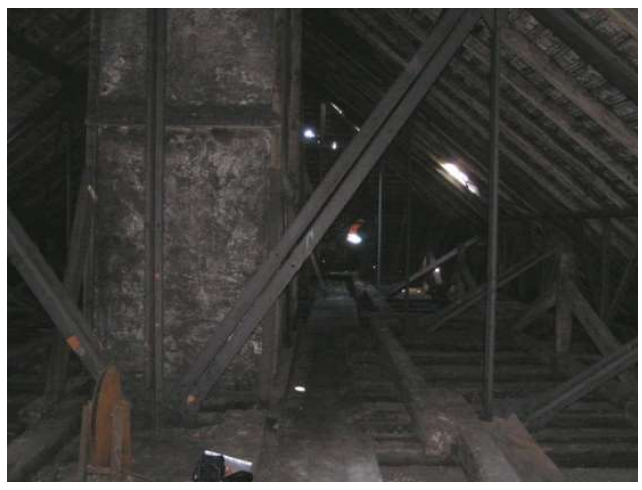

Fig. 5. A fragment of a roof girder: the steel trussed purlin and the wooden structure

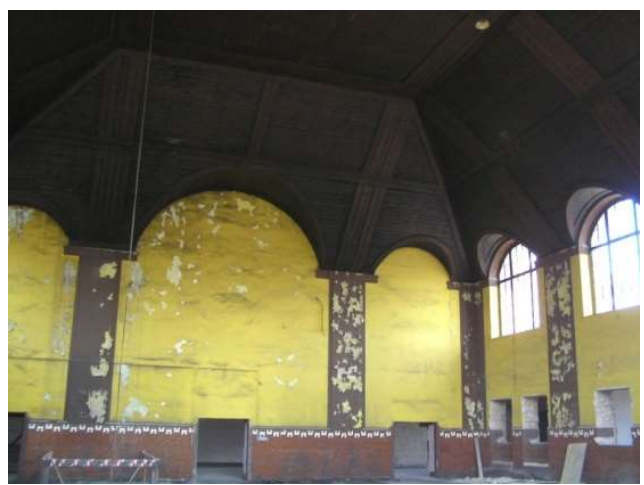

Fig. 6. The wooden ceiling in the waiting room (the southern wing)

The tower roof is a pyramid with eight walls. It has a wooden rafter framing supported on the walls (directly and through steel binding joists). The roof slope is covered with ceramic roofing tiles on wooden battens.

The original structure included riveted steel water tanks embedded in the two upper floors.

All the facade surfaces of the facility are faced with hollow clinker shape bricks, including a range of special-purpose shape bricks (cornices, heads, window opening edges and other).

The above description of the building in question shows clearly that it includes material and structural solutions typical of its period - see [6]. 


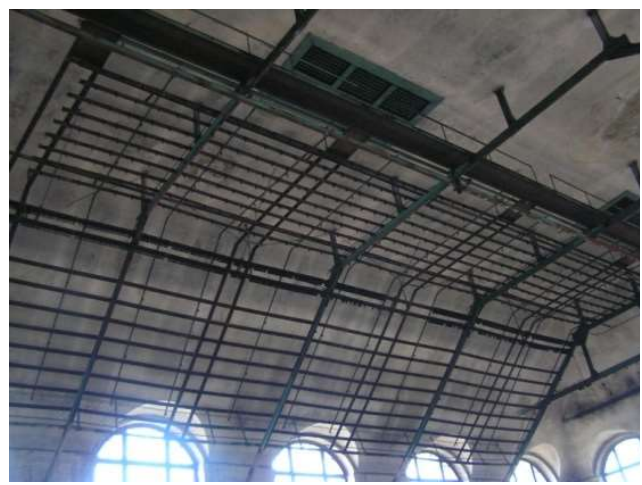

Fig. 7. The reinforced concrete ceiling in the chain bath (the northern wing)

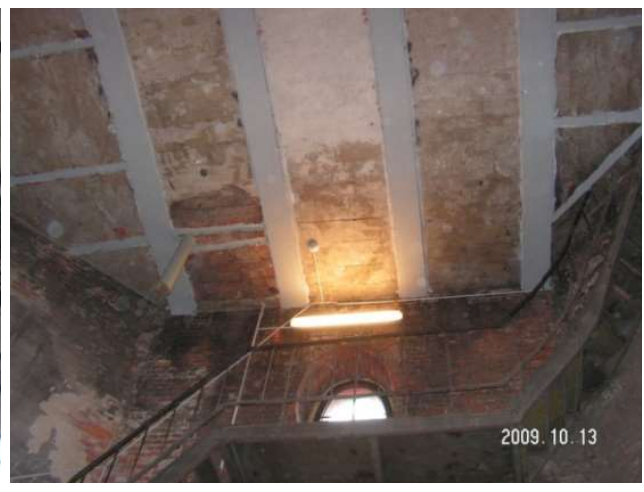

Fig. 8. The lower surface of the tower ceiling: the lower flanges of the beams as well as a fragment of the encircling steel stairs

\section{Technical condition of the building before the overhaul}

The building was unused and unheated for several years that passed from mine liquidation to overhaul commencement. During that period, it was partially devastated, especially in the scope of its finishing elements. In previous years, the building had been intensely used, including its bath function, which had continuously exposed its certain structural elements to moisture and flooding. All that, together with lack of overhauls (including facade overhauls) for many years, contributed to a range of damage. Moreover, many minor modifications were made during the period of improper building use. A part of those led to structural damage. The most significant defects and signs of damage include:

- intense local corrosion of certain steel beams (ribs and binding joists) in all ceilings; the strongest corrosion is found within the lower flange of the I-beam section (Fig. 3),

- $\quad$ significant sagging of a part of ceilings above the first floor (Fig. 4),

- $\quad$ significant damage to the pillar heads in the cellars - vertical cracks running from the ends of the steel beams resting on the pillars (Fig. 9),

- numerous unprotected cut-through spots in the ceilings and walls,

- scratches on and damage to certain window heads,

- local corrosion of the roof structure - intense on the wooden elements (Fig. 10), especially those going beyond the wall outline, as well as on certain steel elements,

- damaged and leaking roofing (of varying intensity) - the roofing paper and the roofing tiles,

- damaged clinker facade layer with missing bricks (of varying intensity), especially on the tower (Fig. 11, 12),

- damage to and partial destruction of the encircling steel stairs of the tower.

Regardless of the above, the soil and hydrographic conditions under the northern wing of the building changed at an unknown moment. It was probably related to the progressing liquidation of the mine waste heap located next to the facility, which caused partial decompression of the substrate. The result was significant cracking of the walls in the northeastern corner of the building as well as clearly visible deformations of the roof structure elements - the outermost girder (Fig. 13) and the braces (Fig. 14). The lower part of the northern wall of the tower (within the attic of the northern wing) was also strongly cracked.

The finishing elements (plasters, floorings, windows and doors) as well as internal systems were virtually destroyed. 


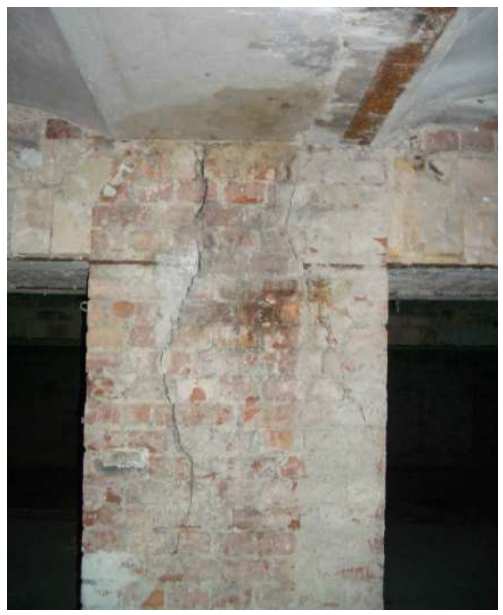

Fig. 9. An example of a cracked pillar in the cellar (see the description in the text)

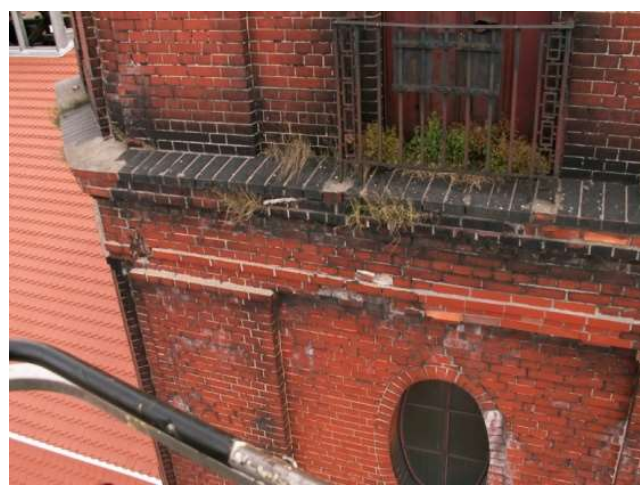

Fig. 11. An example of damage to the clinker facade layer

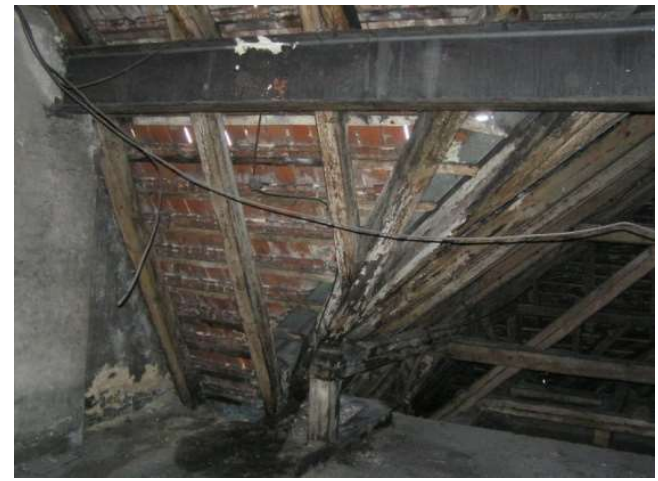

Fig. 10. An example of corrosion of the wooden elements in the roof structure

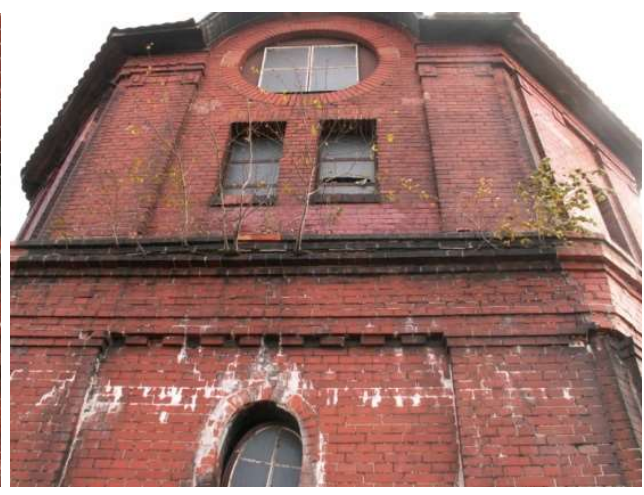

Fig. 12. An example of damage to the clinker facade layer

\section{Scope of the basic modernization works}

The modernization works in the cellars and on the first floor focused on changing the function of individual rooms, retaining their original shape to the greatest extent possible (allowing for light partition walls if necessary). Therefore, no significant structural changes were made there. Local fragments of the load-bearing structures (walls or pillars) did have to be removed, but those were rare cases.

However, significant changes were made to both main rooms of the second floor - the waiting room (in the northern wing) and the bath (in the southern wing). The original dimensions of those rooms in the top view were approx. $20.5 \times 27.8 \mathrm{~m}$, while their approximate clear height reached $13.2 \mathrm{~m}$. The new function of the facility did not require such big rooms, so a decision was made to divide them both vertically and horizontally. An analysis of the existing load-bearing structure (including the foundations) revealed that it was impossible to add any load. Thus, it became necessary to build an entirely new load-bearing structure seated on independent foundations. Due to the possible settlement differences, that structure had to be separated from the original load-bearing structure by expansion joints. 
The described space housed, among other things, lecture halls (including the main lecture hall for 300 people with an amphitheater layout), other education and administrative rooms as well as traffic spaces (Fig. 15).

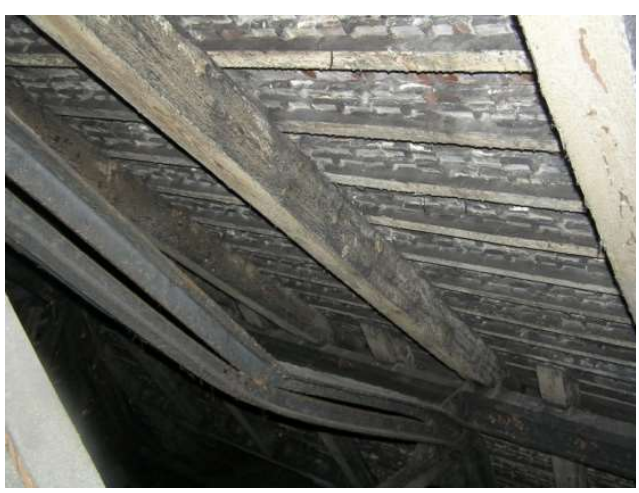

Fig. 13. A deformed upper flange of the girder on the northern side (description in the text)

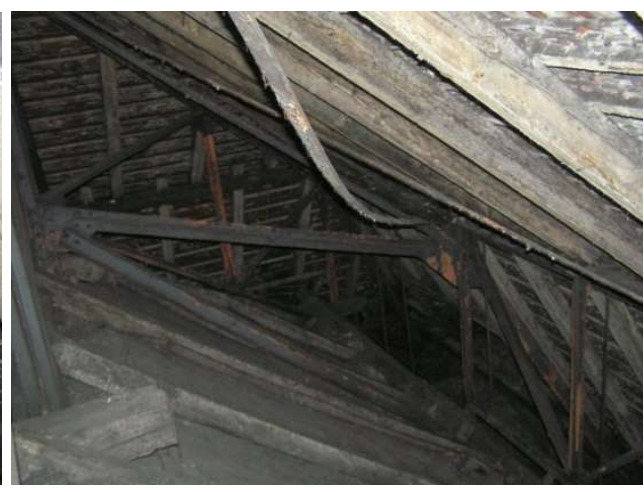

Fig. 14. A deformed brace on the northern side (description in the text)

The new structure in both rooms was designed as a reinforced concrete spatial skeleton seated on reinforced concrete foundation bases. In execution terms, the entire structure had to be monolithic because it was impossible to bring big prefabricated elements or appropriate assembly equipment into the building.

From the practical point of view, one had to solve the basic problem: the necessity of avoiding a collision of the new structure with the original one. The new structure had to be put through two ceiling levels (brick vaults above the cellar and the infill floor above the first floor) without disturbing the steel ribs and binding joists (Fig. 16). At the same time, one had to place new foundation bases among the existing ones. That was an especially difficult task because the original brick foundations had large cross-sectional dimensions. The facility is located in the Kłodnica River ice-marginal valley on relatively weak soils, which caused additional difficulties. For a certain time, the designers even considered building the new structure as a steel one (to reduce the dead load), but the new foundation bases were eventually successfully placed among the existing ones.

A load-bearing structure of a passenger elevator was designed in the main hall. It is an independent steel skeleton seated on its own foundation.

Regardless of the above, a server room with emergency power supply was later established on the upper floors of the tower. It was possible despite a very big weight of the structure itself and of the devices built in it (including battery packs) because the server room was built in the location of one of the former water tanks. Its total weight does not exceed the weight of the tank filled with water and is transferred to the steel load-bearing skeleton of the tower like before. 


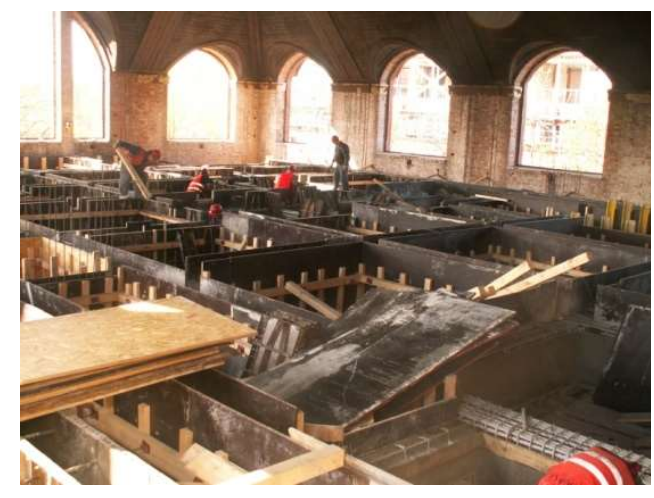

Fig. 15. Shuttering of the new load-bearing structure in the southern wing

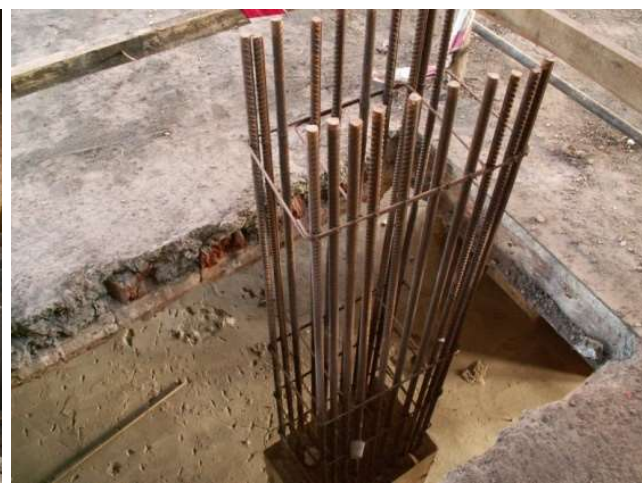

Fig. 16. Passage of a pillar of the new RC structure through the ceiling above the first floor

\section{Overhaul and modernization works - recommendations}

The works designed in the building had two aims. The first (obvious) one was restoration of the appropriate technical condition of all the structural, finishing and system elements. However, that was influenced by the function change, the basic scope of which is described in clause 4 herein. Therefore, the planned works exceeded the typical scope of a restoration overhaul. During the design and the overhaul-adaptation works, special attention was also paid to preservation of an appropriate safety level both of the structure and the executed works. For historic structures, especially facilities with brick structures showing a wide range of damage, it is important to analyze the risk which may result in a hazardous situation [7]. This concerns not only the design state before the commencement of construction works, but also the execution of those works till investment completion. Such situation took place, among other things, in the final phase of the adaptation works, when it turned out that the mechanical ventilation devices (located on the cellar level) required drilling a significant number of additional openings in brick load-bearing walls or enlarging the openings already made (Fig. 17). That forced additional calculation analyses and designing of appropriate reinforcements, against the possibility of causing a failure [8].

The scope of works of the restoration overhaul stemmed directly from the defects and damage described above. The historic nature of the facility, the facade (put under the heritage conservator supervision) and selected elements of the interior constituted a certain difficulty. The general overhaul recommendations were as follows:

- $\quad$ strengthening of the corroded steel beams in the ceilings. Depending on the damage degree and beam location, steel supporting elements in the form of additional binding joists and pillars were installed; moreover, steel sections were locally supplemented;

- strengthening of the damaged brick pillars in the cellars by covering them with concrete and additional reinforcement or enclosing them with a steel structure. In both cases, the strengthening was carried out from the foundation coping to the steel beams resting on the pillar; the load-bearing capacity of the strengthening element ensured transfer of the entire force acting on the pillar;

- supplementation of openings, preserving the original nature of the structure to the greatest extent possible;

- rebricking, with local injections to fill the scratches in the structural elements;

- replacement of the corroded wooden elements of the rafter framing as well as impregnation and fire protection of the remaining ones; 
- replacement of the roofing and a full repair of the facade, including replacement of the damaged shape bricks with original ones obtained from another disassembled facility from the same period.

An observation of the damaged building corner revealed that it was already stable. Therefore, it was recommended to rebrick the damaged wall fragments (including installation of horizontal reinforcement) and replace the deformed elements of the roof girder and the braces. A similar recommendation concerned rebricking of and installing additional reinforcement on the scratched fragment of the northern wall of the tower.

It was also recommended to install encircling ties hidden under the clinker facade on the ceiling level of the tower (Fig. 18).

The construction of the new load-bearing structure involved appropriate recommendations in the scope of the technology of performing openings in the ceilings, including steel elements stabilizing the ceramic filling next to the openings.

After completing all the works, it was recommended to clean the entire clinker facade, point it and protect its surface with a hydrophobizing preparation.

The main tasks of the authors of the paper were to perform an expert study on technical condition of the existing structure and to prepare guidelines for renovation process. In addition, the geometry of the new structures was consulted in the view of the possibility of their build-in (especially to avoid collisions with the existing load-bearing elements). However, the authors of the paper did not take part in the actual design of the new loadbearing structures - hence they have not been described in detail here.

Additionally, the volume of the text does not allow for the presentation of the detailed schemes.

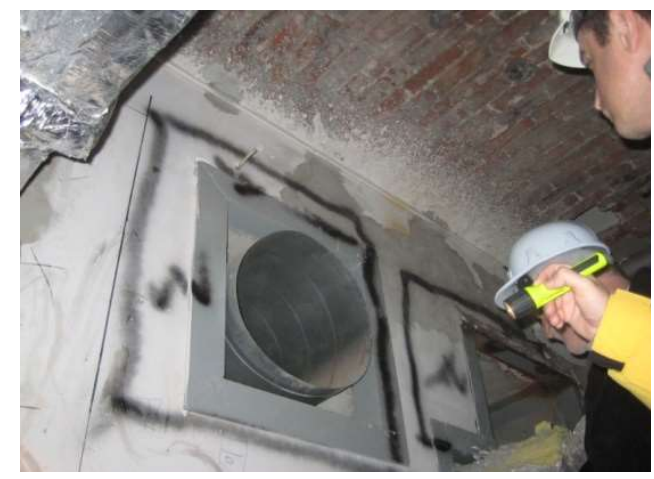

Fig. 17. The existing openings in a load-bearing wall and their enlarging outline

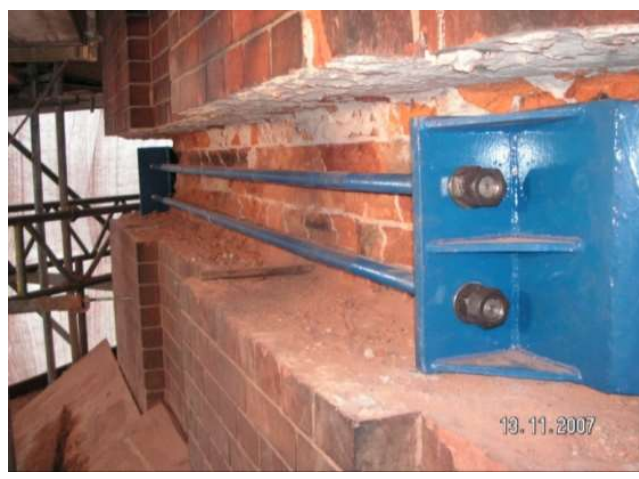

Fig. 18. Assembly of one of the encircling ties of the tower

\section{Summary}

The rapid development of industry in Upper Silesia at the turn of the $19^{\text {th }}$ and $20^{\text {th }}$ centuries resulted in a number of industrial buildings with a significant cubic capacity. Most of them were regular production halls, but some also fulfilled other functions allowing for giving them untypical shapes. A characteristic feature of industrial construction in that period was its care for the esthetic aspect of the building beside its usefulness. This manifested itself in using high-class construction materials (including frequent application of clinker bricks) as well as paying huge attention to proportions and proper integration of the facilities into the surrounding landscape. Details of brick buildings were performed with great care using a range of untypical ceramic shape bricks to form heads, small pillars and cornices. 
Formal industrial buildings were often created by renowned architects specializing in comprehensive design of not only industrial facilities themselves, but also their accompanying housing estates and other related buildings.

After World War II, the approach to industrial architecture changed significantly. A large number of new facilities was built only with the function in mind and made of the cheapest materials available, which further influenced their already questionable appearance. Unfortunately, such approach also concerned the existing facilities: they were not overhauled for years and often modified or redeveloped in a way disturbing their architect's original vision. Additional problems appeared in the last decade of the $20^{\text {th }}$ century, when many industrial plants collapsed, bringing about devastation and demolition of numerous facilities. Only for a short time have industrial buildings been treated as monuments and put under appropriate control and heritage conservator supervision.

Given the above, the waiting room and bath building of the former Gliwice Mine as well as the neighboring engine house were truly lucky. Till 2000, when the mine was closed, the building in question was used according to its original purpose and did not undergo significant redevelopments. Then, after a few years of standing unused, it underwent a comprehensive overhaul planned and implemented with preservation of the original structure, especially the facade with all its details. Consequently, the facility regained its original splendor, becoming one of the most interesting Upper Silesian buildings of this type and one of the city's showpieces. The described building is an example of the correct and creative approach to industrial architecture monuments.

This paper is published thanks to the project no. BK-235/RB6/2017.

\section{References}

1. P. Deutsch, Die oberschlesische Montanindustrie vor und nach der Teilung des Industriereviers, Bonn (1926)

2. W. Stumpe, Güteverbesserung des oberschlesischen Hochofenkokses, Stahl und Eisen, $34(1962)$

3. K. König, Der Steinkohlenbergbau in Oberschlesien von 1945-1955. Wissenschaftliche Beiträge zur Geschichte und Landeskunde Ost-Mitteleuropas. Herausgegeben vom Johann Gottfried Herder-Institut, Marburg (1958)

4. Jahrbuch für den Oberbergamtsbezirk Breslau, Phönix-Verlag. Kattowitz, Breslau, Berlin (1913)

5. L. Schofer, The Formation of a Modern Labour Force, Upper Silesia 1865-1914 University of California Press Ltd. (1975)

6. Stahl im Hochbau. Taschenbuch für Entwurf, Berechnung und Ausführung von Stahlbauten. 10. Auflage, Verein Deutscher Eisenhüttenleute im NS.-Bund Deutscher Technik, Düsseldorf (1938)

7. D. Sorin, B. Corneliu, B. Catalin, I. Liana Risk Assessment and Rehabilitation of Historical Masonry Buildings. Advance in Economics, Law and Political Sciences, Proc. of the 3rd Int. Conf. on Risk Management, Assessment and Mitigation (RIMA'14); Proc. of the 3rd Int. Conf. on Economics, Political and Law Science (EPLS'14); Proc. of the $3 r d$ Int. Conf. on Finance, Accounting and Auditing (FAA'14), Brasov, Romania, 221225, (2014)

8. J. Krentowski, T. Chyzy, P. Dunaj, Sudden collapse of a 19th-century masonry structure during its renovation process, Engineering Failure Analysis, 82, 540-553, (2017) 